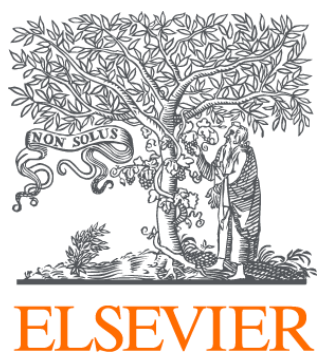

Since January 2020 Elsevier has created a COVID-19 resource centre with free information in English and Mandarin on the novel coronavirus COVID-

19. The COVID-19 resource centre is hosted on Elsevier Connect, the company's public news and information website.

Elsevier hereby grants permission to make all its COVID-19-related research that is available on the COVID-19 resource centre - including this research content - immediately available in PubMed Central and other publicly funded repositories, such as the WHO COVID database with rights for unrestricted research re-use and analyses in any form or by any means with acknowledgement of the original source. These permissions are granted for free by Elsevier for as long as the COVID-19 resource centre remains active. 
Short communication

\title{
A novel method for making human monoclonal antibodies
}

\author{
J. Fraussen $^{\text {a }}$, K. Vrolix ${ }^{\text {b }}$, P. Martinez-Martinez ${ }^{\text {b }}$, M. Losen ${ }^{\text {b }}$, E. Meulemans ${ }^{\text {c }}$, M.H. De Baets ${ }^{\text {a,b }}$, \\ P. Stinissen ${ }^{a}$, V. Somers ${ }^{a, *}$ \\ ${ }^{a}$ Hasselt University, Biomedical Research Institute and Transnationale Universiteit Limburg, School of Life Sciences, Diepenbeek, Belgium \\ ${ }^{\mathrm{b}}$ Department of Neuroscience, School of Mental Health and Neuroscience, Maastricht University, Maastricht, The Netherlands \\ ${ }^{\mathrm{c}}$ Department of Pathology, Academic Hospital Maastricht, Maastricht, The Netherlands
}

\section{A R T I C L E I N F O}

\section{Article history:}

Received 5 March 2010

Received in revised form

1 May 2010

Accepted 12 May 2010

\section{Keywords:}

B cell immortalization

Epstein-Barr virus

Monoclonal antibodies

B cell spectratyping

\begin{abstract}
A B S T R A C T
We have developed a B cell immortalization method for low B cell numbers per well using simultaneous B cell stimulation by CpG2006 and B cell infection by Epstein-Barr virus (EBV), followed by an additional CpG2006 and interleukin-2 (IL-2) stimulus. Using this method, immunoglobulin G (IgG)-producing immortalized B cell lines were generated from peripheral blood $\operatorname{IgG}^{+} \mathrm{CD} 22^{+} \mathrm{B}$ cells with an efficiency of up to $83 \%$. Antibody can already be obtained from the culture supernatant after 3-4 weeks. Moreover, clonality analysis demonstrated monoclonality in $87 \%$ of the resulting immortalized B cell lines. Given the high immortalization efficiency and monoclonality rate, evidence is provided that no further subcloning is necessary. An important application of this B cell immortalization method is the characterization of (autoreactive) antibodies from patients with autoimmune disease. This could eventually lead to the identification of new autoantigens, disease markers or targets for therapy.
\end{abstract}

(C) 2010 Elsevier Ltd. All rights reserved.

\section{Introduction}

B cell immortalization by Epstein-Barr virus (EBV) is an established method for antibody production. EBV infects B cells via their CD21 receptor [1] and subsequently transforms them into continually dividing, lymphoblastoid cell lines that produce antibodies representing the humoral immune response in vivo. Antibodies can be generated against an infectious agent or tumour cells, rendering the resulting antibodies attractive for therapy. In addition, B cell immortalization can be a valuable tool for the production and characterization of autoreactive antibodies from patients with autoimmune diseases. This can provide more insight into the underlying mechanisms of humoral immune responses in autoimmunity and can lead to the identification of new autoantigens, disease markers or targets for therapy [2-4]. The major advantage of $\mathrm{B}$ cell immortalization, when compared to other antibodyproducing techniques [5-10], is the generation of fully human antibodies that truly reflect both the specificity and diversity of the

\footnotetext{
* Corresponding author. Hasselt University, Biomedical Research Institute, Agoralaan, Building C, 3590 Diepenbeek, Belgium. Tel: +32 11 269202; Fax: +32 11 269299

E-mail address: veerle.somers@uhasselt.be (V. Somers).
}

human immune response, generated from the human B cell repertoire, without the need for specific immunization.

The original B cell immortalization technology, first described in 1977, was performed by culturing B cells in the presence of EBV, obtained from the marmoset lymphocyte cell line B95-8 [11,12]. The resulting immortalized $B$ cell lines were mainly unstable immunoglobulin $\mathrm{M}$ (IgM) producing clones with low affinity. Various adjustments to the procedure have been tried since then, but immortalization and B cell growth rate remained inefficient. More recently, antibodies neutralizing SARS coronavirus and cytomegalovirus (CMV) were produced successfully by the introduction of the polyclonal B cell activator CpG2006 in the B cell immortalization process or by B cell activation prior to EBV infection, respectively [13,14]. In our hands, these methods resulted in a low reproducibility. The current study was aimed at developing a B cell immortalization procedure with a high efficiency and reproducibility when seeding low B cell numbers per well, that could easily be adopted for the production of (autoreactive) antibodies from patients with autoimmune disease. Such a method can be especially advantageous when autoreactive $B$ cells are not easily available, for example in the cerebrospinal fluid (CSF) of multiple sclerosis (MS) patients or the synovial fluid of rheumatoid arthritis (RA) patients. Moreover, seeding low $B$ cell numbers per well limits the bias towards the preferential outgrowth of fast growing immortalized B cells. 


\section{Materials and methods}

\subsection{B cell immortalization procedure}

Peripheral blood from healthy donors was obtained with informed consent. Peripheral blood mononuclear cells (PBMC) were isolated by Ficoll Hypaque density gradient centrifugation (Sigma-Aldrich). To isolate $\operatorname{IgG}^{+} \mathrm{CD}_{22}{ }^{+}$B cells, PBMC were stained with PE-Cy5-labelled anti-CD22 antibodies (Ab) and PE-labelled anti-IgG $\mathrm{Ab}$ for $30 \mathrm{~min}$ at $4{ }^{\circ} \mathrm{C}$ and subsequently enriched by means of FACS sorting using a FACSAria II cell sorter (all from BD Biosciences). The FACS sorted cells were immediately used for B cell immortalization assays.

$\mathrm{IgG}^{+} \mathrm{CD} 22^{+}$B cells were cultured in U-bottom 96-well plates (Nunc) at 50 cells per well in RPMI 1640 medium supplemented with L-glutamine, $10 \mathrm{mM}$ HEPES buffer, $1 \mathrm{mM}$ sodium pyruvate, 50 $\mathrm{U} / \mathrm{ml}$ penicillin, $50 \mu \mathrm{g} / \mathrm{ml}$ streptomycin (all from Invitrogen Life Technologies) and 10\% heat-inactivated fetal bovine serum (FBS, HyClone). All immortalization experiments were started in 30 wells for each tested condition. The isolated B cells were immortalized during 2 weeks in the presence of $1 \times 10^{5}$ autologous irradiated (83 Gy) feeder cells, 30\% v/v EBV-containing supernatant $\left(3.4 \times 10^{8}\right.$ viral copies/ml) of the B95-8 cell line (ATCC) and $1 \mu \mathrm{g} / \mathrm{ml} \mathrm{CpG2006}$
(ODN2006, 5'-tcgtcgttttgtcgttttgtcgtt-3', InvivoGen) (Fig. 1). Next, cells were restimulated during 7 days with $1 \mu \mathrm{g} / \mathrm{ml}$ CpG2006 together with $50 \mathrm{U} / \mathrm{ml}$ IL-2 (Roche Diagnostics). Culture medium was then replaced and cells were continuously cultured without extra stimuli. Immortalization was verified 28 days after seeding by screening the culture supernatant for antibody production using dot blot analysis and by light microscopic examination of cell growth. Both parameters were included since positive antibody measurements were sometimes observed in the absence of B cell growth, due to B cell activation at the start of the culture.

\subsection{Dot blot analysis for antibody production}

Culture supernatant $(5 \mu \mathrm{l})$ of potentially immortalized B cells was spotted on a nitrocellulose blotting membrane (Protran BA-85, VWR International). After drying, blots were blocked with $5 \%(\mathrm{w} / \mathrm{v})$ non-fat dry milk (NFDM) in PBS (blocking buffer) during $30 \mathrm{~min}$ on a shaker. Membranes were then incubated for $1 \mathrm{~h}$ with HRP-labelled rabbit anti-human IgG (Dako) 1/100 in blocking buffer and extensively washed in PBS supplemented with $0.05 \%$ $(\mathrm{v} / \mathrm{v})$ Triton X-100. Antibody production was detected using 3,3' deaminobenzidine (DAB) substrate (Sigma-Aldrich). Serial dilutions of human IgG (Zymed, Invitrogen) ranging from $500 \mu \mathrm{g} / \mathrm{ml}$ to

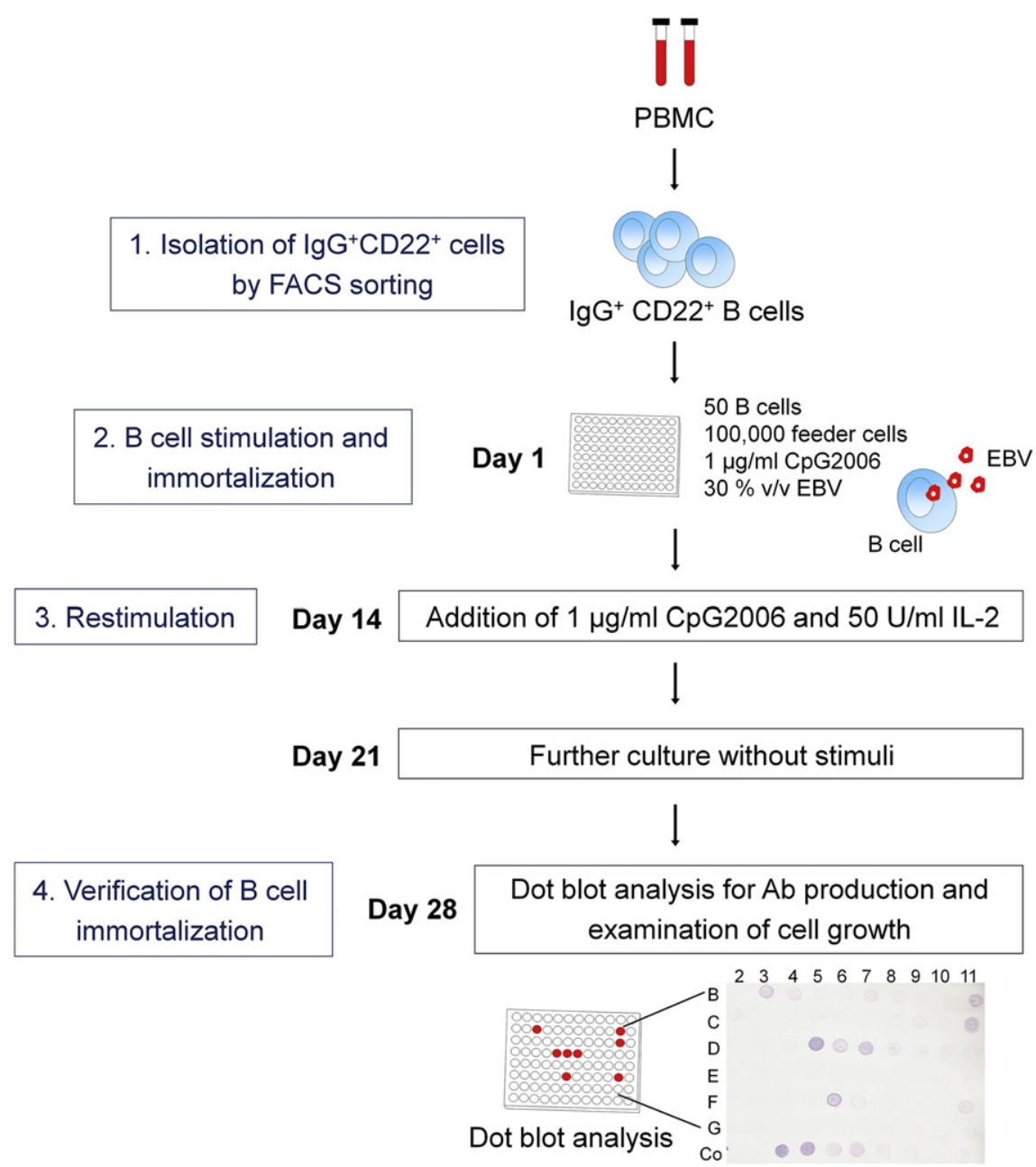

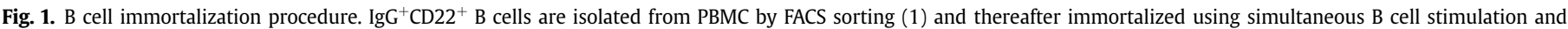

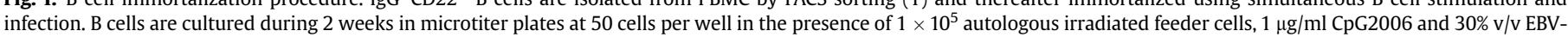

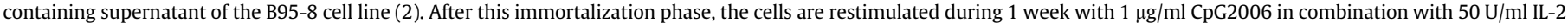

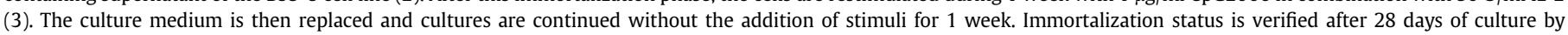
performing dot blot analysis for antibody production and by light microscopic examination of cell growth (4). 
Table 1

Sequences of $\mathrm{VH}$ and $\mathrm{J}$ gene-specific primers.

\begin{tabular}{|c|c|}
\hline Target region & Sequence \\
\hline VH1-FR1 & 5' GGCCTCAGTGAAGGTCTCCTGCAAG 3' \\
\hline VH2-FR1 & 5' GTCTGGTCCTACGCTGGTGAAACCC $3^{\prime}$ \\
\hline VH3-FR1 & 5' CTGGGGGGTCCCTGAGACTCTCCTG 3' \\
\hline VH4-FR1 & 5' CTTCGGAGACCCTGTCCCTCACCTG 3' \\
\hline VH5-FR1 & 5' CGGGGAGTCTCTGAAGATCTCCTGT 3' \\
\hline VH6-FR1 & 5' TCGCAGACCCTCTCACTCACCTGTG 3' \\
\hline VH1-FR2 & 5' CTGGGTGCGACAGGCCCCTGGACAA 3' \\
\hline VH2-FR2 & 5' TGGATCCGTCAGCCCCCAGGGAAGG 3' \\
\hline VH3-FR2 & 5' GGTCCGCCAGGCTCCAGGAA 3' \\
\hline VH4-FR2 & 5' TGGATCCGCCAGCCCCCAGGGAAGG 3' \\
\hline VH5-FR2 & 5' GGGTGCGCCAGATGCCCGGGAAAGG 3' \\
\hline VH6-FR2 & $5^{\prime}$ TGGATCAGGCAGTCCCCATCGAGAG 3' \\
\hline VH7-FR2 & 5' TTGGGTGCGACAGGCCCCTGGACAA 3' \\
\hline VH1-FR3 & $5^{\prime}$ TGGAGCTGAGCAGCCTGAGATCTGA 3' \\
\hline VH2-FR3 & 5' CAATGACCAACATGGACCCTGTGGA 3' \\
\hline VH3-FR3 & $5^{\prime}$ TCTGCAAATGAACAGCCTGAGAGCC $3^{\prime}$ \\
\hline VH4-FR3 & 5' GAGCTCTGTGACCGCCGCGGACACG 3' \\
\hline VH5-FR3 & 5' CAGCACCGCCTACCTGCAGTGGAGC 3' \\
\hline VH6-FR3 & 5' GTTCTCCCTGCAGCTGAACTCTGTG 3' \\
\hline VH7-FR3 & 5' CAGCACGGCATATCTGCAGATCAG 3' \\
\hline $\mathrm{J}$ & 5' CTTACCTGAGGAGACGGTGACC 3' \\
\hline
\end{tabular}

$0.5 \mu \mathrm{g} / \mathrm{ml}$ were included as a positive control. Culture medium was used as a negative control.

\subsection{B cell spectratyping}

B cell spectratyping was performed on 34 randomly selected B cell lines to determine monoclonality rates of the resulting immortalized B cell populations. Genomic DNA was isolated from immortalized antibody-producing and growth-positive $\mathrm{B}$ cells present in single wells. The variable region of the $B$ cell receptor heavy chain (HC) locus was amplified from 100 ng DNA using the IdentiClone ${ }^{\mathrm{TM}}$ IGH Gene Clonality Assay (Invivoscribe Technologies) according to the manufacturer's recommendations. This standardized assay was extensively validated using Revised European/American Lymphoma (REAL) Classification [15]. Primers that target the conserved framework regions (FR) were used in combination with a FAMlabelled consensus primer targeting the conserved joining region $(\mathrm{J})$ in order to amplify the variable region in which genetic rearrangements occur during B cell development. The B cell receptor genes are highly polymorphic and subject to diversity and mutations. To maximize identification of the clonal rearrangements, a polymerase chain reaction (PCR) was performed for each FR using VH familyspecific forward primers (Table 1). Analysis of the resulting fragments was accomplished using automatic capillary electrophoresis (ABI3730, Applied Biosystems). Polyclonal populations resulted in a Gaussian distribution of amplification products with different lengths, while a monoclonal population yielded a single amplification product. This spectratyping procedure can detect clonal populations with a sensitivity of $0.5-5 \%$.

\subsection{Statistics}

All statistical analyses were performed using Prism software version 4.00 (Graphpad). We analyzed the data using unpaired Student's $t$-test. A $p$ value of $<0.05$ was considered statistically significant.

\section{Results and discussion}

An improved B cell immortalization method was developed for the fast generation of IgG-producing B cell lines from $\mathrm{IgG}^{+} \mathrm{CD} 22^{+}$ peripheral blood $\mathrm{B}$ cells. This procedure is characterized by simultaneous B cell stimulation by CpG2006 and B cell infection by EBV during 2 weeks at 50 cells per well (Fig. 1). After this immortalization phase, the cells are restimulated during 7 days by CpG2006 and IL-2.

FACS sorting for the isolation of $\operatorname{IgG}^{+} \mathrm{CD} 22^{+}$cells resulted in the highest yield $\left(1.4 \times 10^{4}\right.$ cells out of $\left.1 \times 10^{7} \mathrm{PBMC}\right)$, purity $(>99 \%)$ and immortalization efficiency (83\%, donor 3 in Fig. 2a) when compared to magnetic selection alone or in combination with FACS sorting (data not shown). No IgM ${ }^{+}$immortalized B cell lines were recovered after FACS sorting, although several $\operatorname{IgM}^{+}$wells could be found after magnetic selection. Consequently, $\operatorname{IgG}^{+} \mathrm{CD} 22^{+}$FACS sorting was proven to be the best choice for $\operatorname{IgG}^{+} \mathrm{B}$ cell isolation prior to B cell immortalization. This enrichment of $\operatorname{IgG}^{+}$B cells before immortalization was performed to select for IgG-producing immortalized B cell lines. Autoantibodies of the IgG isotype are mostly implicated in the pathogenesis of autoimmune diseases. For example, oligoclonal IgG bands (OCB) have been described in the CSF of patients with MS and are used as a diagnostic indicator $[16,17]$. In several autoimmune diseases, including myasthenia gravis (MG) [18,19], systemic lupus erythematosus (SLE) and RA [20], IgG responses against autoantigenic targets are present. Therefore, it is interesting to focus on IgG responses when examining humoral immunity in autoimmune diseases.

The high immortalization efficiency on FACS sorted cells (83\%) was confirmed on 2 other healthy donors (donors 1-2 Fig. 2a). Considering all 3 individual immortalization experiments, an immortalization efficiency of $53-83 \%$ could be achieved (Fig. 2a). Variations in culture conditions were tested together with the immortalization experiments in donors 1 and 2 (Fig. 2b). A mean a

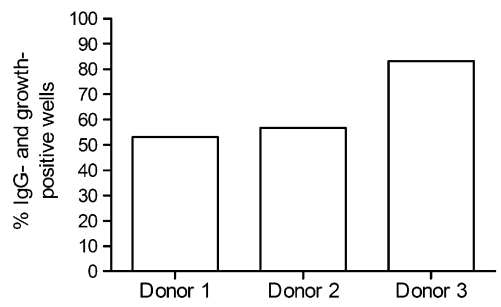

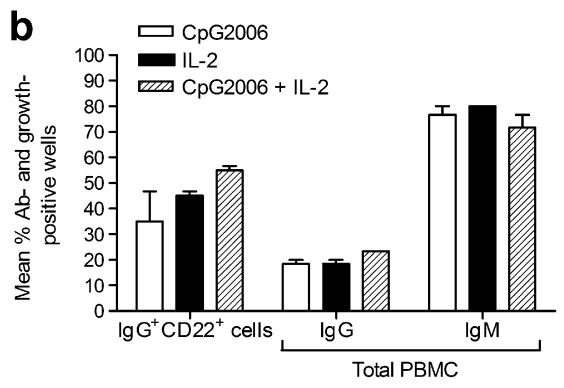
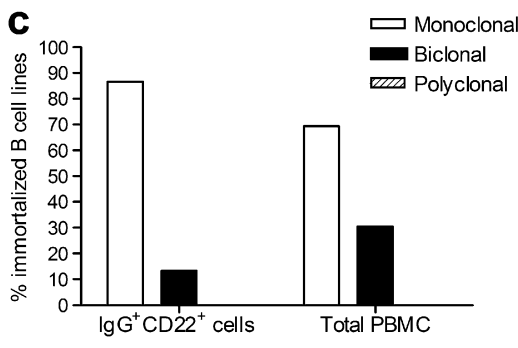

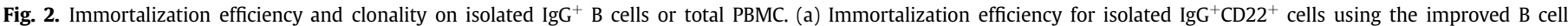

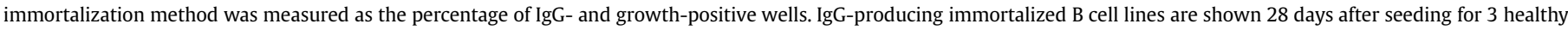

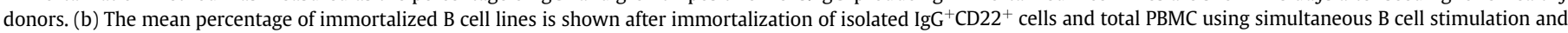

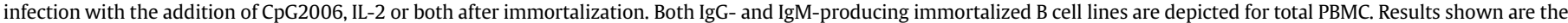

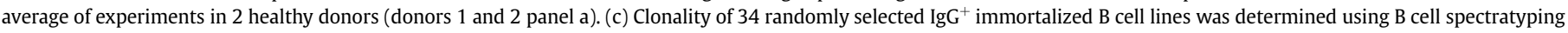
for $\mathrm{IgG}^{+} \mathrm{CD} 22^{+}$cells and total PBMC. The percentage of monoclonal, biclonal and polyclonal immortalized B cell lines is shown. 
immortalization efficiency of 55\% was hereby obtained for the improved method, as indicated by the mean percentage of IgG- and growth-positive wells (Fig. 2b). Variation in CpG2006 and IL-2 concentration revealed that the most efficient $\mathrm{B}$ cell stimulation and immortalization could be obtained with $1 \mu \mathrm{g} / \mathrm{ml}$ CpG2006, without the addition of IL-2 during EBV infection (data not shown). CpG2006 was used for B cell stimulation during immortalization as it was previously shown that this ligand of Toll-like receptor 9 (TLR9) [21] increases immortalization efficiency when administered during EBV infection [13] and causes polyclonal B cell activation and proliferation [22-24]. Some studies revealed that CpG2006 suppresses viral infection as it protects against several viruses $[25,26]$ and induces the production of anti-viral cytokines and other proteins $[27,28]$. Concerning EBV, CpG2006 has only been shown to suppress the initiation of lytic EBV infection via inhibition of lytic gene expression [28]. Such connection, however, has never been demonstrated for latent EBV infection during B cell immortalization in vitro. Moreover, we have shown a positive effect of CpG2006 on B cell activation and a higher immortalization efficiency when CpG2006 is administered to cells when immortalization is in progress (data not shown). In contrast to the increase that has been described in CpG2006 elicited B cell activation [29] or immortalization [30] by IL-2, we could not detect an amplification of B cell immortalization when IL-2 was administered during the B cell immortalization phase (data not shown). Since the IL-2 receptor is mainly present on activated B cells [31], it is likely that IL-2 exerts a stimulating effect on B cell proliferation and growth rather than on B cell activation. This is also reflected in the higher immortalization efficiency when CpG2006 and IL-2 are combined for restimulation in comparison with the addition of CpG2006 or IL-2 alone (Fig. 2a), although the difference was not statistically significant. Addition of CpG2006 increases the effect of IL-2 given that TLR9 expression is elevated after EBV infection and CpG2006 stimulation [32], rendering the immortalized cells even more responsive to $\mathrm{CpG} 2006$.

B cell spectratyping provides further insights into the clonality of the resulting immortalized $B$ cells, which can be useful to evaluate the need for cloning of the B cell lines. A monoclonality rate of $87 \%$ was demonstrated, while the remaining $13 \%$ of the investigated B cell lines appeared to be biclonal (Fig. 2c). This preferential generation of monoclonal immortalized $B$ cell lines can be explained by the immortalization process itself. EBV-infected B cells undergo a proliferative crisis in which most of the cells die because of apoptosis. Surviving B cells become activated and eventually transform into lymphoblastoid immortalized cell lines [33]. Consequently, the outgrowth of multiple immortalized B cell lines is rare when starting with low B cell numbers per well. Nevertheless, the high monoclonality rate provides a major advantage for our B cell immortalization method in combination with the high immortalization efficiency. Subcloning using limiting dilution is no longer necessary, which considerably reduces the time span in which monoclonal antibodies can be produced.

The improved B cell immortalization procedure could also be successfully performed on total PBMC of 2 healthy donors with 95\% efficiency. The same donors were used as in previous experiments with isolated $\mathrm{IgG}^{+} \mathrm{CD} 22^{+} \mathrm{B}$ cells. However, the largest proportion of the resulting B cell lines (72\%) appeared to be $\operatorname{IgM}^{+}$. Only $23 \%$ of the immortalized B cell lines were IgG ${ }^{+}$(Fig. 2b). This larger proportion of IgM-producing immortalized cells was reasonable, as most B cells in the peripheral blood belong to the naïve $B$ cell population [34]. Naïve B cells also express the EBV receptor CD21 (unpublished results) and can be activated by CpG2006 to produce large amounts of IgM [23]. Moreover, the percentages of $\operatorname{IgM}^{+}$and IgG $^{+}$immortalized B cell lines that were produced from total PBMC, namely $72 \%$ and $23 \%$, resemble the proportion of naïve and memory B cells present in the peripheral blood [35]. No significant difference could be observed when CpG2006, IL-2 or both were used during restimulation after $\mathrm{B}$ cell immortalization, although a trend towards a higher percentage of $\mathrm{IgG}^{+}$immortalized B cells was observed when both stimuli were added to the culture (23\%) compared to a single stimulus (18\%) (Fig. 2b). When immortalizing total PBMC, $250 \mathrm{ng} / \mathrm{ml}$ cyclosporine A has to be added to suppress growth of (cytotoxic) T cells that would otherwise target EBVinfected B cells, causing immortalization failure. B cell spectratyping of the generated immortalized B cell lines resulted in $70 \%$ monoclonal B cell lines and 30\% biclonal B cell lines (Fig. 2c). This again emphasizes a high monoclonality rate when seeding low $\mathrm{B}$ cell numbers per well.

Using this improved B cell immortalization method, we have successfully generated a large panel of immortalized B cell lines from the peripheral blood of MS patients [36,37]. Some B cell lines could also be recovered from the CSF of a MS patient. Preliminary screening demonstrated intracellular binding of antibodies from several B cell lines to a human oligodendroglia cell line, suggesting autoreactivity. In addition, autoreactivity against striated muscle proteins was shown for immortalized B cell lines that were recovered from MG patients [19,38]. These are two examples of how possibly autoreactive antibodies can be produced from patients with autoimmune disease using B cell immortalization.

In summary, this study presents a reproducible B cell immortalization method with an efficiency of up to $83 \%$ for fast IgG production from $\mathrm{CD}_{22}{ }^{+} \mathrm{IgG}^{+}$peripheral blood B cells, by simultaneous B cell stimulation using CpG2006 and B cell infection by EBV followed by an additional stimulus of CpG2006 and IL-2. This immortalization procedure can in addition be used for IgM production from total PBMC with an efficiency of about $70 \%$. A detailed method description is provided to increase reproducibility of B cell immortalization success rates. Moreover, B cell spectratyping demonstrated monoclonality in almost $90 \%$ of the immortalized B cell lines originating from isolated $\operatorname{IgG}^{+} \mathrm{B}$ cells. This unique combination of a high immortalization efficiency and a high monoclonality rate eliminates the need for further cloning of the immortalized cells. For the first time, a B cell immortalization procedure is introduced with high efficiency and reproducibility for low B cell numbers that makes immediate generation of monoclonal antibodies possible.

\section{Acknowledgments}

We thank Igna Rutten for technical assistance. This work was supported by grants from Hasselt University, the Transnationale Universiteit Limburg and MYASTAID LSHM-CT-2006-037833.

\section{References}

[1] Martin DR, Marlowe RL, Ahearn JM. Determination of the role for CD21 during Epstein-Barr virus infection of B-lymphoblastoid cells. J Virol 1994;68 (8):4716-26.

[2] Somers K, Govarts C, Stinissen P, Somers V. Multiplexing approaches for autoantibody profiling in multiple sclerosis. Autoimmun Rev 2009;8 (7):573-9.

[3] Somers V, Govarts C, Somers K, Hupperts R, Medaer R, Stinissen P. Autoantibody profiling in multiple sclerosis reveals novel antigenic candidates. J Immunol 2008;180(6):3957-63.

[4] Govarts C, Somers K, Hupperts R, Stinissen P, Somers V. Analysis of antibody reactivity in paired cerebrospinal fluid and serum of a relapsing remitting multiple sclerosis patient. Autoimmunity 2009;42(8):699-704.

[5] Carter PJ. Potent antibody therapeutics by design. Nat Rev Immunol 2006;6 (5):343-57.

[6] Kohler G, Milstein C. Continuous cultures of fused cells secreting antibody of predefined specificity. Nature 1975;256(5517):495-7.

[7] Levy R, Dilley J. Rescue of immunoglobulin secretion from human neoplastic lymphoid cells by somatic cell hybridization. Proc Natl Acad Sci U.S.A 1978;75 (5):2411-5. 
[8] McCafferty J, Griffiths AD, Winter G, Chiswell DJ. Phage antibodies: filamentous phage displaying antibody variable domains. Nature 1990;348(6301): $552-4$.

[9] Olsson L, Kaplan HS. Human-human hybridomas producing monoclonal antibodies of predefined antigenic specificity. Proc Natl Acad Sci U.S.A 1980;77(9):5429-31.

[10] Meijer PJ, Andersen PS, Haahr HM, Steinaa L, Jensen A, Lantto J, et al. Isolation of human antibody repertoires with preservation of the natural heavy and light chain pairing. J Mol Biol 2006;358(3):764-72.

[11] Rosen A, Gergely P, Jondal M, Klein G, Britton S. Polyclonal Ig production after Epstein-Barr virus infection of human lymphocytes in vitro. Nature 1977;267 (5606):52-4.

[12] Steinitz M, Klein G, Koskimies S, Makel O. EB virus-induced B lymphocyte cell lines producing specific antibody. Nature 1977;269(5627):420-2.

[13] Traggiai E, Becker S, Subbarao K, Kolesnikova L, Uematsu Y, Gismondo MR, et al. An efficient method to make human monoclonal antibodies from memory B cells: potent neutralization of SARS coronavirus. Nat Med 2004;10 (8):871-5.

[14] Funaro A, Gribaudo G, Luganini A, Ortolan E, Lo BN, Vicenzi E, et al. Generation of potent neutralizing human monoclonal antibodies against cytomegalovirus infection from immune B cells. BMC Biotechnol 2008;8:85

[15] van Dongen JJ, Langerak AW, Bruggemann M, Evans PA, Hummel M, Lavender FL, et al. Design and standardization of PCR primers and protocols for detection of clonal immunoglobulin and T-cell receptor gene recombinations in suspect lymphoproliferations: report of the BIOMED-2 Concerted Action BMH4-CT98-3936. Leukemia 2003;17(12):2257-317.

[16] Cross AH, Trotter JL, Lyons J. B cells and antibodies in CNS demyelinating disease. J Neuroimmunol 2001;112(1-2):1-14.

[17] Kabat EA, Glusman M, Knaub V. Quantitative estimation of the albumin and gamma-globulin in normal and pathological cerebrospinal fluid by immunochemical methods. Am J Med 1948;4:653-62.

[18] Graus YF, De Baets MH, Parren PW, Berrih-Aknin S, Wokke J, Breda Vriesman PJ, et al. Human anti-nicotinic acetylcholine receptor recombinant Fab fragments isolated from thymus-derived phage display libraries from myasthenia gravis patients reflect predominant specificities in serum and block the action of pathogenic serum antibodies. J Immunol 1997;158(4):1919-29.

[19] Vrolix K, Fraussen J, Molenaar PC, Losen M, Somers V, Stinissen P, et al. The auto-antigen repertoire in myasthenia gravis. Autoimmunity; 2010.

[20] Weissmann G. Rheumatoid arthritis and systemic lupus erythematosus as immune complex diseases. Bull NYU Hosp Jt Dis 2009;67(3):251-3.

[21] Hurst J, von Landenberg P. Toll-like receptors and autoimmunity. Autoimmun Rev 2008;7(3):204-8.

[22] Bernasconi NL, Traggiai E, Lanzavecchia A. Maintenance of serological memory by polyclonal activation of human memory B cells. Science $2002 ; 298$ (5601):2199-202.

[23] Hanten JA, Vasilakos JP, Riter CL, Neys L, Lipson KE, Alkan SS, et al. Comparison of human B cell activation by TLR7 and TLR9 agonists. BMC Immunol 2008;9:39.
[24] Hartmann G, Weeratna RD, Ballas ZK, Payette P, Blackwell S, Suparto I, et al Delineation of a CpG phosphorothioate oligodeoxynucleotide for activating primate immune responses in vitro and in vivo. J Immunol 2000;164 (3):1617-24.

[25] Schlaepfer E, Audige A, von Beust B, Manolova V, Weber M, Joller H, et al. CpG oligodeoxynucleotides block human immunodeficiency virus type 1 replication in human lymphoid tissue infected ex vivo. J Virol 2004;78(22):12344-54.

[26] Luganini A, Caposio P, Landolfo S, Gribaudo G. Phosphorothioate-modified oligodeoxynucleotides inhibit human cytomegalovirus replication by blocking virus entry. Antimicrob Agents Chemother 2008;52(3):1111-20.

[27] Kato A, Homma T, Batchelor J, Hashimoto N, Imai S, Wakiguchi H, et al Interferon-alpha/beta receptor-mediated selective induction of a gene cluster by CpG oligodeoxynucleotide 2006. BMC Immunol 2003;4:8

[28] Ladell K, Dorner M, Zauner L, Berger C, Zucol F, Bernasconi M, et al. Immune activation suppresses initiation of lytic Epstein-Barr virus infection. Cell Microbiol 2007;9(8):2055-69.

[29] Liang H, Nishioka Y, Reich CF, Pisetsky DS, Lipsky PE. Activation of human B cells by phosphorothioate oligodeoxynucleotides. J Clin Invest 1996;98(5): 1119-29.

[30] Lanzavecchia A, inventors; Monoclonal antibody production by EBV transformation of B cells. WO/2004/076677. 2004 Sept. 10.

[31] Muraguchi A, Kehrl JH, Longo DL, Volkman DJ, Smith KA, Fauci AS. Interleukin 2 receptors on human $B$ cells. Implications for the role of interleukin 2 in human B cell function. J Exp Med 1985;161(1):181-97.

[32] Bourke E, Bosisio D, Golay J, Polentarutti N, Mantovani A. The toll-like receptor repertoire of human B lymphocytes: inducible and selective expression of TLR9 and TLR10 in normal and transformed cells. Blood 2003;102(3):956-63.

[33] Sugimoto M, Tahara H, Ide T, Furuichi Y. Steps involved in immortalization and tumorigenesis in human B-lymphoblastoid cell lines transformed by Epstein-Barr virus. Cancer Res 2004;64(10):3361-4.

[34] Fraussen J, Vrolix K, Martinez-Martinez P, Losen M, De Baets MH, Stinissen P, et al. B cell characterization and reactivity analysis in multiple sclerosis. Autoimmun. Rev. 2009;8(8):654-8.

[35] Chong Y, Ikematsu H, Yamaji K, Nishimura M, Nabeshima S, Kashiwagi S, et al. CD27(+) (memory) B cell decrease and apoptosis-resistant CD27(-) (naive) B cell increase in aged humans: implications for age-related peripheral B cell developmental disturbances. Int Immunol 2005;17(4):383-90.

[36] Fraussen J, Vrolix K, Martinez-Martinez P, Hupperts R, Van Diepen A, Meulemans E, et al. Antibody-producing monoclonal B cell lines from multiple sclerosis patients obtained by $\mathrm{B}$ cell immortalization. Clin Immuno 2009;131:S129-30.

[37] Fraussen J, Martinez P, De Baets M, Van Diepen A, Meulemans E, Stinissen P, et al. Characterizing autoantibodies in multiple sclerosis by $\mathrm{B}$ cell immortalization. J Neuroimmunol 2008;203(2):183-4.

[38] Vrolix K, Fraussen J, Meulemans E, Becker P, Phernambucq M, Somers V, et al. Monoclonal antibody production by immortalization of $\mathrm{B}$ cells from the thymus of myasthenia gravis patients. J Neuroimmunol 2008;203(2):258. 